\title{
Folk Psychological Narratives and the Case of Autism ${ }^{1}$ \\ Daniel D. Hutto
}

\begin{abstract}
This paper builds on the insights of Jerome Bruner by underlining the central importance of narratives explaining actions in terms of reasons, arguing that by giving due attention to the central roles that they play in our everyday understanding of others provides a better way of explicating the nature and source of that activity than does simulation theory, theory-theory or some union of the two. However, although I promote Bruner's basic claims about the roles narratives play in this everyday enterprise, I take issue with his characterization of the nature of narrative itself. In so doing, important questions are brought to the fore about what makes our understanding of narratives possible. In line with the idea that we ought to tell a developmental story that looks to the social arena for the source of narratives about reasons, I promote the idea that what is minimally required for becoming conversant in such everyday narratives need not be anything as sophisticated as a theory of mind or a capacity for simulation. The paper concludes using evidence concerning autism as a test case to help support this conclusion.
\end{abstract}

\section{The Function of Narratives in Commonsense Psychology}

Recognising that the bulk of our normal attempts to understand one another take place in second-personal, social contexts, Bruner claims that narratives play two vital roles in commonsense psychology. ${ }^{2}$ The first is to shape our expectations by making us familiar with a vast stock and wide range of 'ordinary' situations and related actions, which

$1 \mathrm{I}$ am indebted to the National Endowment for the Humanities for providing a stipend to attend Robert Gordon's summer seminar on theory-theory and simulation theory in June and July 1999. Many of the views expressed in this paper have been influenced by discussions with my fellow seminarians and by the fine series of talks organised by Bob Gordon. I am also grateful to the those who commented upon the paper at the Ninth Annual Meeting of the European Society for Philosophy and Psychology 2001, especially Bob Gordon and Alvin Goldman. Finally, I would like to thank those who commented on earlier versions of the idea presented here, especially my colleagues at Hertfordshire; those who took part in the Leeds Senior Seminar in February 2002 and those who attended my talks at the University of Lund in September 2002.

2 I make the case for approaching folk psychology from this direction at length in Hutto (forthcoming). 
enables us to judge their appropriateness. The thought is that narratives provide an important platform for enabling our initial determination of which actions are acceptable; what sort of events are important and what sorts of explanations constitute giving good reasons. Rather than merely providing a framework for disinterested prediction and behaviour of others, as Bruner puts it, 'folk psychology' acts as an instrument of culture by providing us with the grounds for our normal expectations. He claims of the 'canonical status of folk psychology' that, 'it summarizes not simply how things are but (often implicitly) how they should be' (Bruner 1990, p. 40). Stories-real or fictional-teach us what others can expect from us but just as importantly, what we can expect from others. Thus, in learning commonsense psychology by listening to and trading narratives we develop a common sense of what is 'obvious' and 'significant'.

Naturally this claim about commonsense psychology dovetails with the idea that storytelling is central to moral education and the development of ethical points of view (see Morton 2003, ch.1 \& 2). Like more direct forms of training, much story-telling functions to impart norms; instilling and inculcating values in children even if only indirectly. This holds out real promise of dispelling the long-standing worries about how we first acquire our commonsense psychology. If narratives play a central role in supplying us with this evaluative framework it is easy to see how it might be acquired from others. Nearly all children have parents, teachers and others who tell them stories during their formative pre-school years and onwards (cf. Ashington 1996). Giving attention to this is an attractive alternative to having to explain: how we get better at deploying a pre-existing theory of mind; or how our innate theory modules upgrade themselves in appropriate stages (and explaining how and why we have them in the first place); or how children fashion a common folk 'theory' through experimental trial and error (see Fodor 1995; Segal 1996; Gopnik 1996, respectively).

Even more importantly Bruner's observations serve to remind us of something absolutely crucial, but often overlooked, about the pragmatic contexts and occasions in which we need to supply commonsense 
psychological explanations. He notes, 'When things 'are as they should be', the narratives of folk psychology are unnecessary' (Bruner 1990, p. 40). Explanations are only sought in the sorts of cases in which we are surprised or perplexed by another's actions or they by ours.

This underscores the vital explanatory role that narratives sometimes play. They mediate when others deviate from our expectations, functioning as normalising explanations that enable us to cope with unusual or eccentric actions. In domestic cases this is usually achieved by supplying missing details that allow us to see an action as already fitting within a familiar framework, thus the narrative shows that the action is, despite appearances, really within the fold of the ordinary. Alternatively, narratives can make actions familiar. For in listening to another's account we sometimes expand the scope of what we deem acceptable. This is normally achieved when the other fleshes out on a larger canvas why they took an action, sometimes introducing a different set of values, such that we are brought to see it in a new light. Or, more conservatively, we may at least begin to see why the action might 'make sense' to them, even if it still leaves us cold. This sort of 'negotiation' is only possible if one is already fluent in the idiom of what is normal for in trying to understand another's alien or novel take on events we must hold our norms up against theirs as objects of comparison. This is what it is to relate the familiar to the strange or the domestic to the foreign.

This upsets the orthodox idea that all that is required for 'making sense of' or 'rationalising' the behaviour of others is that we identify which mental states causally explain their actions, locating these within the well-known framework that outlines how propositional attitudes interact appropriately with each other, as epitomised by the practical syllogism (cf. Hutto 1999b, p. 12-3, 25-6). On the prevalent view, in order to explain a particular action we have but to subsume it under a general law that reveals the relation between the events in question to be that of the cause and the caused. However, if this is all that is required I could, in a very unilluminating way, explain why I swallowed an acorn by appeal to the fact that I believed it be just that while averring my desire 
to consume acorns. Assuming that this explanation correctly identifies the reason for action, this project is not irrational. There is no conflict between my stated beliefs and desires, yet it remains utterly puzzling. This shows that, at least in some cases, the mere citing of a reason, even when fits appropriately with the other relevant beliefs and desires and even assuming its is causally responsible for the action in question, does not suffice to explain an action in the strong sense of making it intelligible. Worse still, in most cases in which we are puzzled by another's action simply being told that $\mathrm{X}$ performed the action for such and such a reason will leave us none the wiser as to why it was performed. To achieve this requires the kind of narrative mediation described above. It is for this reason that we ought to follow Bruner in holding that the practical explanations of commonsense psychology have a narrative as opposed to a conceptual form (see Bruner, 1990 p. 35).

Traditionalists may insist that even if wider narratives serve to make sense of the 'explanation of the action' in such cases, technically only the citing the reason really explains it. However we are inclined to jump on this metaphysical issue, for the pragmatic purposes of commonsense psychology it is clear that it is only when we enlist such narratives that the important work gets done. Whatever its other merits, the unembedded model of what is involved in the explanation of action, which harkens back to Hempel, is flawed in this arena precisely because it pays no heed to the pragmatic context in which commonsense psychological explanations operate. It does not concern itself with questions of for whom the explanation is issued or who is giving it or why. Yet to understand commonsense psychology properly requires attending to just such matters. The importance of this injunction is clear if we accept that we only need such normalising explanations in cases in which the actions of others appear to be aberrant.

In giving such explanations exactly which details are significant and how much explaining is needed, will vary from one case to the next. In ordinary dialogues this is hammered out practically. Good explanations are only complete when the other understands; when enough has been 
said to make an action intelligible. It is for this reason that in homely cases in which we draw on the same canonical stock of norms we are usually only interested in short stories, not novels.

Of course, it is not always possible to make another intelligible in either of the ways cited above. Sometimes the 'behaviour' of others is so erratic and strange that we have no option but to regard them in the same light as we might 'objects'. Stich, who once observed that folk psychology is best regarded as a kind of domestic anthropology, provided us with a number of cases of exotic subjects, such as children, animals and confused or demented persons who fall outside its explanatory scope (see Stich 1983, p. 163). Faced with others of these sorts we may have to resort to the postulation of theoretical inner states of a non-mentalistic variety to explain their behaviour. Still it should be clear that this sort of manoeuvre is only necessary when our normal way of understanding others breaks down and no mediating narratives of any kind are of any use. But such limitations do not detract from the fact that commonsense psychology, 'has powerful means that are purposebuilt for rendering the exceptional and the unusual into comprehensible form' (Bruner 1990, p. 47).

\section{Narrative Understanding and Autism}

Even if narratives serve the kinds of practical functions described above, including the crucial one of directing us to look for a socially grounded account of how we first develop our commonsense psychology, it might be supposed all the same that there is nothing intrinsic to their nature that explains how we come to produce or understand them. Indeed, Bruner's musings about what distinguishes narratives from other types of discourse leads him to speculate about their defining characteristics in precisely a way that opens the door to this sort of concern. He tells us that:

Perhaps its principal property is its inherent sequentiality: narrative is composed of a unique sequence of events, mental states, happenings 
involving human beings as characters or actors. These are its constituents (Bruner 1990, p. 43).

He augments this, adding that, 'these constituents do not, as it were, have a life or a meaning of their own' (Bruner 1990, p. 43). This is conferred interdependently by their configuration in a plot. He then unpacks this appeal to the configuration in a larger plot by including 'drama' on the list of necessary features of all narratives. In turn, he unpacks what is required for understanding 'drama' by appeal to our understanding of 'persons and their actions' or analogues thereof. But if we follow suit then this sort of account will shed little further light on how we come to understand narratives concerning reasons for action. For Bruner's robust characterisation of the nature of narratives builds in too much, entailing as it does that to understand narratives already presupposes, at least implicitly, a capacity to understand persons. For explanatory purposes this is clearly circular.

However, there are more minimal characterisations of the nature of narratives available that avoid this consequence. For example, Larmarque and Olsen tell us that, 'The crucial element is a temporal one: events, not merely states of affairs, must be represented and connected in narrative' (Larmarque and Olsen 1994, p. 225). It is easy to combine this more neutral characterisation with the idea that different types of narratives can be classed according to their various constituents, which need not involve persons or reasons for action at all. It is known already that the kinds of main characters that provide the focus of our stories are legion. They are not just about people, if only implicitly, but can include accounts of such inanimate things as, say, the careers of balloons on windy days.

In allowing that narratives come in such different varieties, an important question looms: What enables us to understand narratives of the sort involving persons who act for reasons? Might it be that just here theory-theory or simulation heuristics might re-enter, through the backdoor as it were? For it seems possible to ask which kinds of imaginative or cognitive abilities make possible our competent dealings 
with the special kinds of narratives that concern persons who act for reasons. One might agree with Bruner about the functions of narratives vis-à-vis folk psychology while maintaining, nonetheless, that our understanding of and ability to generate such narratives must rest either on a competence in deploying a 'theory of mind' or on a capacity to engage in simulative imagination.

Evidence from autism can appear to point towards some such conclusion, for it is well known that autistics have profound difficulties both in interacting with and understanding others and understanding stories about their sophisticated intentional actions. Despite this they have no general problem in constructing narratives, as is shown by the fact that they have no parallel problem in dealing with stories concerning 'mechanical' or 'behavioural/functional' events. This was revealed in a number of experiments requiring the correct sequencing of cartoon frames involving these different types of narrative (see BaronCohen, 1995, p. 72, Frith 1989, 163-5).

These facts about autistics provide an ideal point of comparison with the normal case. In what follows I briefly review the evidence associated with the syndrome, challenging the dominant claims that the lack of a properly functioning theory of mind (or part thereof) or a capacity for simulation is what explains it. I reject these claims because theorytheoretic and most simulation accounts-specifically those that regard the process as involving a kind of projection-take for granted that when we understand others we are in the business of ascribing causally efficacious mental states to them. This presupposes that one is already capable of recognising others as appropriate targets for mentalistic ascription. Yet it is far from clear that autistics are even in a position to do this.

Given that other minds are effectively treated as 'black boxes', it is easy to see that theory-theorists make such an assumption, but the same is true of most simulationists as well. The dominant focus of the debate that rages between these two rivals concerns how we ordinarily make reliable ascriptions not whether we do. Simulationists claim not that we come to understand others by means of theoretical generalisations but 
instead rely on a rather complex form of imaginative projection, usually thought to be based on some type of introspective modelling (cf. Gopnik and Wellman 1992, p. 159, see also Baron-Cohen and Cross 1992, Perner 1996, p. 90, see also Hutto 1997, p. 63-7). But on this construal, which is quite common in the literature, it must be assumed that we start from our own perspective and only then project our thinking onto another. Indeed, it has been argued when set out in this way the last step in the simulative process always requires at least an implicit appeal to, 'a general premise stating that the model is relevantly similar to the [thing modelled]' (Fuller 1995, p. 22).

For this reason, many hold simulation approaches should be classed as a sub-species of theory-theory. This follows if we accept that any appeal to knowledge or background assumptions of any sort constitutes 'operating with a theory', as Jackson has recently claimed, accordingly making the truth of theory-theory, 'near enough analytic' (Jackson 1999, p. 80). Currie and Ravenscroft also highlight this commitment on the part of simulationists when they observe that, "Simulation' as it is currently used, is ambiguous; it has a narrower and a broader meaning. Suppose I try to predict your behaviour by imagining myself in your situation. There are three things that must go on if I am to get the answer by simulation. The first is to acquire knowledge, or at least some beliefs, about your situation. The second thing is for me to place myself, in imagination in that situation and to see, what, in imagination, I decide. The third is to draw a conclusion from this about what you will do. Sometimes 'simulation' refers to the whole three-tier process, sometimes just to the bit in the middle' (Currie and Ravenscroft 2003, p. 54). Insisting that simulation must be understood in its broader sense, they are inclined to agree with Jackson at least in holding that, 'simulations never work without assistance from theory' (Currie and Ravenscroft 2003, p. 54, emphasis mine).

Yet, what of those variants of simulation theory that bill themselves as rejecting the need for inferences from analogy? For example, in advocating what he calls radical simulation, Gordon has persistently 
stressed that simulation should not be understood as process of transportation but rather one of transformation-hence it involves no 'inference from me to you' (Gordon 1995; Gordon 1996, p. 12). In a similar way, Heal holds that in simulation we replicate the target's thoughts in ourselves before observing their consequences (cf. Heal 1998b, p. 491). This process, which she calls co-cognition, requires, 'harness[ing] our own cognitive apparatus and mak[ing] it work in parallel with that of the other' (Heal 1998a, p. 85). Thus importantly, although she holds that conclusions about what another is thinking might be justified by appeal to analogy, she also allows they can be justified simply by assuming that others have a minimal competence in dealing with aspects of a common world (Heal 2000, p. 12).

These approaches are billed as involving only a first-personal methodology, but this ignores the fact that they always take place within contexts in which the simulator is already aware that others will have different viewpoints. This is made explicit by the defenders of such views when they note that 'relevant differences' need to be taken into account if the simulations are to work at all. Thus even if simulation is thought of as first-personally 'transformational' as opposed to 'projective', the process still needs to take place against the backdrop of understanding on the part of the simulator that others have different points of view and, at least potentially, may see things differently. If this were not the case simulation would be an utterly hopeless means of coming to understand another; at best it would be a means of becoming another.

This latter idea is more in tune with second-personal approaches; those that regard our primary intersubjective interactions as a form of 'embodied practice'. It is certainly true that these offer a serious challenge to the idea that we start life making ascriptions to others, implicitly or otherwise (see Hutto 2000, ch. 1, sec. 3, 2002, Gallagher 2001). Accordingly, our basic modes of interaction are thought not to privilege either first- or third-personal perspectives, as these only come into view at a much later stage of development. There are reasons to favour this understanding of our most basic interactions. For example, 
characterising basic shared responses, such as imitation or motor mimicry, in terms of the making of inferentially governed ascriptions or as a kind of modelling of others on ourselves gets the direction of affection back to front. It is not that we project ourselves onto the other, but rather that we are moved by or mirror them and vice versa. Challenging the dominant metaphor, McVeer gets it just right when she remarks, 'attunement does not depend on putting ourselves in others' shoes. We are already in their shoes. We are already in their shoes, as they are in ours' (McVeer 2001 p. 121).

It is not only straightforward, but usually irresistible, for us: to perceive that 'another' is looking; to see that another exhibits purposeful agency, having goals and desires; or to respond to another's basic emotions. Unless we reign ourselves in, we 'see' and 'react to' these forms of expressive agency even where there are no agents to manifest them, as is shown by our automatic responses to such things as a series of illuminated dots, if they are arranged and move in the right sort of way. To characterise this as a kind of 'mind reading' suggests an unfortunate and overly intellectualised picture of the underlying processes. Gallagher, who uses the lingo of 'body reading', is nearer the mark for he reminds us that our basic interactions with others are such that, 'one perceives the emotion in the movement and expression of the other's body' (cf. Gallagher 2001, p. 90). The same goes for the detection of basic desires, intentions and agency. However, talk of 'reading' may still mislead. Liberated of the idea that perception and response are related in crude input and output terms, perhaps we can better understand such basic modes of interaction as rooted in specialised kinds of nonconceptual perception (Hurley 1998, cf. Baron-Cohen 1995, p. 33-43).

Noting this is important because, as seen by their performance with behavioural narratives, autistics are not completely impaired in understanding or responding to this sort of 'agency'. ${ }^{3}$ Like us they too

3 Given this, Simon Baron-Cohen's catchy label 'mindblindness' implies that their central problem for autistics is an inability to 'see other minds'. On the one hand, this clearly overstates the case, since at best autistics are only 'blind' to some aspects of the psychology 
can see what another seeks and desires. But this is possible precisely because seeing and responding to basic intentions, desires and goals can be done without having any understanding of other points of view. In basic cases, seeing that another manifests such-and-such an attitude towards something or that they are expressing such-and-such a simple emotion does not require a reflective stepping outside of one's own perspective on events, let alone projecting such a perspective onto the other.

This is true even of my seeing that another is looking at me or seeing another's seeing something else, although autistics do have difficulties in this regard. They have notable problems sharing attention and generally fail even to meet the eyes of others (see Baron-Cohen, 1995 p. 66). By way of comparison, by the end of their first year, normal babies engage in social referencing and respond, even in experimental conditions when confronted by such things as visual cliffs, only after taking cues from their mothers' emotional orientations. Thus a mother's expressions of happiness or anxiety systematically affect infant reactions. Describing this perhaps too richly Hobson remarks that what such interactions involve is something like the recognition that, 'I am seeing this as a frightening situation, she sees it as OK' (Hobson 1993, p. 235).

All the same it must be stressed that these basic kinds of perception and modes of shared interaction, which might serve as examples of 'unframed' transformational simulations, are not on a par with what is needed to recognise more complex emotions or to understand beliefs. For the latter presuppose a capacity to recognise that the other has their own perspective on events. As noted earlier, autistics have problems here as well. For example, with respect to complex emotions BaronCohen reports that in viewing photographs of people expressing emotions, 'most children with autism were able to match happy and sad, but significantly more children with autism made errors in matching

of others. Certainly, they are not completely 'blind to other minds' as revealed by their facility with basic concepts of desire and agency (see Hutto 1997). 
pictures of surprised expressions. They mistook these for non-cognitive states such as yawning or being hungry, focusing on the open mouth' (Baron-Cohen 1995, p. 79). He opines that this is because surprise is a 'belief-based' emotion, one that is likely to require recognition of the other's particular take on things.

Their difficulties in this regard are also heralded early by their lack of engagement in even very basic forms of pretend play. Hobson holds that this stems, 'from their difficulty in disembedding from a particular point of view and acquiring the capacity to adopt a variety of 'coorientations' to given objects or events, for example to pretend a matchbox 'is' a car' (Hobson 1993, p. 243). Unlike most of us who easily see other possibilities, as manifest by our mature capacity for aspect switching and easy understanding of metaphor and analogy, autistics have ultra literal tendencies. And, as the 'false belief' experiments show, while normal children are usually able to imagine others as having contrasting perspectives on the very same situation by around the age of four, autistics are persistently unable to do this. The fact that normal children engage in pretend play as early as age two suggests that these imaginative feats are at best related, but not identical. The latter minimally involves recognition of the possibility of other perspectives. Autistics lack this ability; by contrast they appear to see the world, as it were, mono-perspectivally. Thus, although it is tempting for as to regard them as simply having an impoverished understanding of others, it is rather that they are unable to recognise others in the sense of regarding them as having any perspectives at all. Very clearly our more sophisticated, social interactions require this. For example to understand someone's acting out of a belief requires being able to regard the other as having a belief, possibly different from our own, about the state of the world.

Given that there are independent reasons to think that we only begin to distinguish between the subjective and the objective as we master the concept of belief, it is not surprising that autistics also display difficulties in grasping the distinction between appearance and reality (see Hutto 
1999b, ch 5, sec. 2, Kern and Marbach 2001, p. 71). In an experiment designed to test their understanding with respect to the former BaronCohen found that, "most children with autism made largely "phenomenalist" errors, saying "It looks like an egg", "It really is an egg”, and similar things' (Baron-Cohen 1995, p. 82) ${ }^{4}$.

It follows from this that it is only at a later stage in our early development that we get into a position to even begin to regard others, and indeed ourselves, as having perspectives. This cannot be explained by a capacity to theorise or simulate (or some combination of the two) since a necessary prerequisite for such activities is the making of mentalistic ascriptions, which is predicated on a prior understanding of there being other perspectives. Without attempting to provide a global characterisation of autism or seeking to postulate a single cause for the multitude of disorders associated with it, I claim these observations point to an appropriately modest proposal about why autistics cannot cope with narratives concerning others. ${ }^{5}$ They lead us to ask: How might this capacity develop in the normal cases?

Putting narrative dialogue centre-stage, it is plausible that our understanding of the possibility of other perspectives is something that develops precisely as and when we begin to give accounts of ourselves and listen to the accounts given by others. Such interpersonal conversations are dynamic affairs; participants must engage with each other, being constantly forced to try to grasp and correct one's account of the other's take on things. In this way, 'Conversation constantly underlines the centrality of point-of-view.' (Harris 1996, p. 218, see also Bohman 2000, p. 227). This proposal is in line with empirical findings

4 Being so impaired would also make problematic the entertaining of counterfactual possibilities of the kind required for future planning, as associated with executive control functions (see Currie 1996, p. 253).

5 It is worth remembering that 'autism' is a broad-church term and its exact application is not well defined. As Boucher notes, 'there is a range of different symptoms associated with different disabilities such as Kanner's and Asperger's Syndromes that are both regarded as forms of autism. This makes it unclear whether in speaking of autism we are talking about a syndrome, with a single common cause, a set of related but different subtypes or something better understood as a continuum' (see Boucher 1996, p. 225-6). 
discussed by Harris. Drawing on the results of Bartsch and Wellman, he notes that children develop the ability to comment on advanced desires (of the sort which are unfulfilled when the world is not accommodating) roughly about six months before they start to do this with advanced beliefs (of the sort that are false if the world is not as it is thought to be). If we assume that both activities already involve a capacity for representational ascription, this time lag wants explaining. But, if we only truly gain a fully-fledged sense of there being other perspectives contemporaneously with our grasp of the concept of the concept of belief, as Davidson has urged, then we should anticipate that there ought to be differences in what is required for understanding 'advanced desires' as opposed to 'advanced beliefs'.

It should be easier for children to grasp the idea that 'another' desires something, even if they are frustrated by its absence, because this is the kind of drama one can see unfolding within a single purview. But it requires something more to be able to grasp that another regards something that is in plain view, incorrectly or differently. Harris draws a similar conclusion, suggesting that to understand another's desires it is sufficient to regard them as 'goal-directed agents', but in order to understand another as an advanced believer requires the more sophisticated ability to see them as 'epistemic subjects'. In effecting this, he holds, 'the child's growing experience, not as an agent, but as a conversationalist plays a critical role' (Harris 1996, p. 209-210). On this basis he explains the late development in our understanding of beliefs by appeal to the fact that, 'a critical pre-condition for understanding beliefs but not desires-participation in the exchange of information through conversation-is not obtained by most children until the third year' (Harris 1996, p. 208).

Looking at matters in this light promises to go a long way in explaining some of the serious downstream problems associated with autism. Returning to an earlier theme, if narratives provide one of the main routes into the norm-ridden social world that most of us occupy, then an inability to cope with them may in turn explain why autistics are 
so socially awkward; showing such a limited capacity to understand such things as jokes or a sensitivity to the ethical dimensions of most situations (see McVeer 2001, p. 113). If a primary function of narratives is to instill norms and to teach us what is appropriate then for those with an impoverished facility with them such limitations ought to be anticipated.

Moreover, if it is mainly through the hearing and digesting stories that we gain a sense of what is appropriate, normal and acceptable this would explain not only why autistics are out of tune socially, but also why they have such trouble seeing what is, 'important, meaningful or relevant' (Frith 1989, p. 109, cf. also 5-6, 12, 108, 120, 134).

\section{Conclusion}

Why then do autistics have such difficulty in understanding and producing narratives involving people who act for reasons? Perhaps this is explained by an inability to recognise that there are other perspectives. I hold this incapacity is much more fundamental than an impairment in mentalistic theorising or simulative ability, since both these presuppose it.

\section{University of Hertfordshire}

\section{References}

Ashington, Janet (1996) 'What Is Theoretical About a Child's Theory of Mind?: A Vygotskian View of Its Development' in P. Smith (ed.) Theories of Theories of Mind Cambridge: Cambridge University Press. Baron-Cohen, Simon (1995) Mindblindness: An Essay on Autism and Theory of Mind. Cambridge MA: MIT Press, 1995.

Baron-Cohen, Simon, and Pippa Cross (1992) 'Reading the Eyes: Evidence for the Development of a Theory of Mind.' Mind and Language 7, no. 1-2: 172-86.

Bruner, Jerome (1990) Acts of Meaning. Cambridge MA: Harvard University Press. 
Carruthers, Peter (1996) 'Simulation and Self-Knowledge: A Defense of Theory-Theory' in P. Smith (ed.) Theories of Theories of Mind Cambridge: Cambridge University Press.

Currie, Gregory (1996) 'Simulation-Theory, Theory-Theory and the Evidence from Autism' in P. Smith (ed.) Theories of Theories of Mind Cambridge: Cambridge University Press.

Frith, Uta. Autism: Explaining the Enigma. Oxford: Blackwell, 1989.

Fuller, Gary (1995) 'Simulation and Psychological Concepts' in Martin Davies (ed.) Mental Simulation Cambridge: Blackwell.

Gordon, Robert M. (1996) 'Radical Simulationism' in P. Smith (ed.) Theories of Theories of Mind Cambridge: Cambridge University Press

_ (1995) 'Simulation without Introspection or Inference from Me to You' in Martin Davies (ed.) Mental Simulation Cambridge: Blackwell. Harris, P. F.(1996) 'Desires, Beliefs and Language.' in P. Smith (ed.) Theories of Theories of Mind Cambridge: Cambridge University Press. Heal, Jane (1998b) 'Co-Cognition and Off-Line Simulation: Two Ways of Understanding the Simulation Approach.' Mind and Language 13(4) 477-98.

- (1998a) 'Understanding Other Minds from the Inside' in Anthony O'Hear (ed.) Current Issues in Philosophy of Mind New York: Cambridge University Press.

Hurley, Susan (1998) Consciousness in Action Cambridge MA: Harvard University Press.

Hutto, Daniel D. (1997) 'The Story of the Self: The Narrative Basis of Self-Development' in Karl Simms (ed.) Critical Studies: Ethics and the Subject Amsterdam: Rodopi.

— (1999b) 'A Cause for Concern: Reasons, Causes and Explanations' in Philosophy and Phenomenological Research 59 (2), 381-401.

— (1999a) The Presence of Mind Amsterdam: John Benjamins. (2000) Beyond Physicalism Amsterdam: John Benjamins. (2002) 'The World Is Not Enough: Shared Emotions and Other Minds' in Peter Goldie (ed.) Understanding Emotions, Aldershot: Ashgate.

_ (forthcoming) 'The Limits of Spectatorial Folk Psychology' in Mind and Language.

Jackson, Frank (1999) 'All That Can Be at Issue in the Theory-Theory Simulation Debate’ Philosophical Papers 28(2) 77-96. 
Lamarque, Peter, and S. Olsen (1994) Truth, Fiction and Literature. Oxford: Oxford University Press.

McVeer, Victoria (2001 'Psycho-Practice, Psycho-Theory and Autism' Journal of Consciousness Studies 8, no. 5-7: 109-32.

Morton, Adam (2003) The Importance of Being Understood London: Routledge.

Perner, Josef (1996) 'Simulation as Explication of Prediction-Implicit Knowledge About the Mind: Arguments for a Simulation-Theory Mix.' in P. Smith (ed.) Theories of Theories of Mind Cambridge: Cambridge University Press.

Stich, Stephen (1983) From Folk Psychology to Cognitive Science Cambridge MA: MIT Press, 1983. 